\title{
Turismo para personas mayores. El caso de Victoria, Entre Ríos, Argentina
}

\section{Tourism for the elderly. The case of Victoria, Entre Ríos, Argentina}

\author{
Valeria Gala \\ Universidad Nacional de Quilmes, Argentina. \\ Contacto: vgala@unq.edu.ar
}

Recibido: mayo de 2018

Aceptado: junio de 2018

\begin{abstract}
Resumen
Este artículo tiene por finalidad definir, a partir de su propia voz, experiencia e imaginario turístico, el perfil del turista mayor y proponer adecuaciones a la oferta turística de Victoria, Entre Ríos. Su voz como sujetos activos que construyen su propio tiempo de ocio. El análisis de la bibliografía muestra que existe un área de vacancia sobre la temática por lo que su estudio es de interés para el sector turístico. Para la recolección de las voces se aplicó una encuesta semi dirigida seguida de conversaciones informales donde se profundizó el imaginario turístico y las percepciones de las personas mayores en cuanto a la oferta turística de la ciudad. A partir de ello, se proponen una serie de adecuaciones para la oferta turística local a fin de fidelizar al segmento.

Palabras clave: persona mayor; turismo; imaginario turístico.
\end{abstract}

\begin{abstract}
This article aims to define, from their own voice, experience and tourist imaginary, the profile of the senior tourist and propose adjustments to the tourist supply of Victoria, Entre Ríos. Their voice as active subjects who build their own leisure time. The analysis of the bibliography shows that there is a loop on the subject, which is why its study is of interest for the tourism industry. For the collection of the voices a semi-directed survey was applied, followed by informal conversations where the tourism imaginary and the perceptions of the elderly in terms of the city's tourist offer was furthered studied. From this, a series of changes are proposed for the local tourist offer in order to loyalize the segment.

Keywords: elderly; tourism; senior tourism; tourist imaginary.
\end{abstract}

\section{Introducción}

El fenómeno de la globalización impacta en todos los campos y la práctica turística no está exenta a ello. Este contexto da origen a nuevas formas de turismo tal como se especializan los mercados para personas mayores (Wallingre, 2009). 
Durante el siglo XX en América Latina y el Caribe se han suscitado importantes cambios demográficos entre los que se observa un acelerado crecimiento de los grupos de personas mayores de 60 años de edad y más. El crecimiento de este segmento es pluricausal. Entre estas se pueden mencionar: la reducción de los niveles de fecundidad y mortalidad, el aumento en la esperanza de vida -que se ha incrementado notablemente-, la mejora en la calidad de vida - producto de avances tecnológicos y médicos- y la jubilación a temprana edad así como estilos de vida más activos.

Particularmente, Argentina es uno de los países latinoamericanos de mayor envejecimiento poblacional. En la última década del siglo $X X$, el envejecimiento de la población argentina abarcó a la casi totalidad de las provincias del país (Aromando, 2002). Acorde con la información censal, la población mayor de 65 años en Argentina ha variado de un $7 \%$ en 1950, a un $13,3 \%$ en el año 2000 y a 10,2\%, promedio país, en el censo 2010 (donde los varones suman el $8,6 \%$ y las mujeres el $11,8 \%$ ); de los cuales solo el $1,5 \%$ vive en residencias de larga estadía. Al respecto, lacub (2012) señala que este dato de adultos institucionalizados es interesante porque es muy bajo en relación a lo que está presente en el imaginario colectivo. La representación social hegemónica que se tiene es que las personas mayores requieren asistencia (Gala, 2017). Asimismo, proyecciones del Fondo de Población de las Naciones Unidas (en adelante, UNFPA) indican que hacia 2050 el $25 \%$ de la población argentina tendrá 60 años o más.

En particular, en Victoria, los resultados del censo 2010 arrojan que la población total asciende a 35.767 habitantes (con una dispersión por sexo de 17.564 hombres y 18.203 mujeres), representando un crecimiento del 4,9\% respecto del censo anterior. En cuanto a la población mayor de 65 años, la ciudad entrerriana bajo estudio, se encuentra por encima del total provincial del 10,3\% con una población mayor a 65 años del 11,57\%.

Entonces, este segmento se vuelve de interés para el sector turístico dado que al haber finalizado su vida laboral y disponer de tiempo y recursos necesarios, este colectivo, puede disponer de su tiempo libre y dedicarlo a realizar, entre otras, actividades recreativas o turísticas (Maldonado Acosta, 2012). Por lo que, si se pretende que el mismo esté satisfecho y pueda volverse fiel a un destino, es necesario conocerlos y capacitarse para brindar una oferta turística adecuada a sus condiciones, motivaciones y disponibilidades. El fin de ello es lograr, como se expresara en la Carta de Recife (Brasil) sobre turismo de personas mayores del año 1996, “...un acceso justo y democrático al turismo" (OMT, 1996, p. 1).

Desde la Organización Mundial del Turismo (en adelante, OMT) como menciona Wallingre (1998), se insta a la estimulación de estrategias que permitan la integración de personas mayores al disfrute del tiempo libre destinado al turismo y la recreación, un tiempo de oportunidad, donde la actividad en sí tiene sentido propio. La práctica turística entonces resulta una de las variables de mayor integración y de valorización de la calidad 
de vida de este segmento de mercado que permite beneficios comerciales y sociales a todos aquellos que interactúan en los mismos (Vivanco Naranjo, 2012).

A partir de lo expuesto, interesa mencionar las palabras de Goycoolea Prado (2004) que señala "...pareciera que todo el mundo sabe cómo son y piensan los turistas, sin replantearse que a menudo se trata de tópicos preestablecidos, cuando no reduccionistas y despectivos" (p. 77).

Surgen entonces algunas interrogantes sobre ¿Cuál es el perfil del turista persona mayor? ¿Es suficiente definirlo desde la perspectiva de la oferta? ¿Cuál es el imaginario turístico? ¿Cómo experimenta este turista la práctica turística?

En este artículo, se propone entonces conocer el perfil del segmento y a partir de la propia voz expresada en el imaginario turístico, construir conocimiento de forma que se puedan realizar propuestas concisas para una mejor adaptación de la oferta de la ciudad de Victoria. Se parte de la idea de que la oferta actual no se ajusta por completo a las necesidades y demandas de este segmento así como las personas mayores tienen y presentan ideas propias acerca de la oferta turística del destino, y en sus argumentaciones expresan alternativas para satisfacer esas necesidades.

En función del enfoque seleccionado se utilizaron metodologías cualitativas entre las que se incluyeron las provenientes de la observación participante y se administraron encuestas semi estructuradas o dirigidas seguidas de conversaciones informales. También se realizó un análisis documental con el objetivo de llevar a cabo la triangulación de datos y un análisis bibliográfico respecto del colectivo de las personas mayores y el turismo, tanto en Argentina como en otros países, que incluyó tanto documentos de organismos internacionales como producciones académicas de distintos niveles, legislación nacional y aquella proveniente de organismos internacionales.

El conocimiento es construido coparticipativamente entre los protagonistas y la investigadora, requiriendo un abordaje en estado natural, en el destino seleccionado y particularmente en los atractivos turísticos que se les ofrecen, a fin de conocer sus argumentaciones para proponer adecuaciones a la oferta turística. El relato permite la transferencia de la experiencia como así también las fotografías.

El universo estuvo constituido por personas mayores (de entre 60 y 80 años) que se encontraban en los atractivos turísticos seleccionados al momento de llevar a cabo las encuestas en el mes de julio de 2015.

Se tomó como corte de la muestra a la población mayor de 60 años ya que la ONU considera persona mayor a aquella de 60 años para los países en desarrollo y, particularmente para Argentina, es el umbral de ingreso a la jubilación -considerando que es la edad jubilatoria de la mujer-y los 80 años el límite del mismo -esto al entender que, a esa edad ya comienza a presentarse dificultades en la movilidad e independencia 
(Alcalá, 2001) y la OMS considera que es el promedio de esperanza de vida femenino para Argentina.

El tamaño de la muestra no estuvo determinado a priori sino que, a partir de lo que señala Stake (2005), se buscó escoger casos viables de abordar en encuentros surgidos en el propio campo y donde las indagaciones fueran bien acogidas y con actores dispuestos a brindar información acerca de su experiencia. Se trató de una muestra aleatoria de cincuenta personas, momento en que se alcanzó la saturación teórica y la información se volvió redundante para las preguntas abiertas.

\section{¿Cuál es el perfil del Turista persona mayor?}

En la revisión bibliográfica se observa que esta modalidad turística no presenta un consenso en su definición. En particular, Le Serre (2008), en su búsqueda por definir el concepto, analiza que en las distintas definiciones del segmento de personas mayores pueden distinguirse elementos que no cambian y se presentan de manera constante, a pesar de los diferentes abordajes que se realizan e industrias desde donde se los concibe. Resume que las características que se mantienen son: constituyen un segmento con alto potencial, en una edad en la cual comienzan a notarse algunos aspectos propios de la edad así como se sienten más jóvenes que lo que indica su edad cronológica -aspectos que conllevan además a un cambio en sus hábitos de consumo. Mientras que los aspectos que se modifican en las distintas definiciones son: la segmentación en términos cronológicos y el retiro/jubilación.

De esta manera, se propone una posible definición de esta modalidad turística como aquella destinada a satisfacer las necesidades de las personas mayores de 60 años, con un espíritu jovial y abierto, un nivel económico medio o medio-alto, la vida resuelta y con ansias de descubrir nuevos lugares.

Por otro lado, interesa definir el perfil de este segmento. Esta cohorte ha experimentado una serie de cambios en distintos ámbitos que, de manera heterogénea, han moldeado su manera de vivir, de concebir sus tiempos, afectando sus valores y deseos, generando hiatos o acercamientos, que son distintos de los aspectos cronológicos que los ubican dentro de un segmento (Chardon, 2011). Este colectivo posee intereses y motivaciones propias que resultan relevantes para el sector turístico.

Al respecto, interesa señalar que el segmento mencionado posee características particulares, tales como: la autosuficiencia tanto en capacidades psíquicas como físicas (Maldonado Acosta, 2012) y que gozan de buena salud. Aunque los cambios biológicos del envejecimiento denotan disminución en sus capacidades funcionales (visual, auditiva, de fuerza, de la reserva funcional del sistema nervioso, de memoria) ello no implica la 
imposibilidad de realizar actividades sino que las mismas deben ser ejecutadas más lentamente.

Particularmente las personas mayores poseen una exigencia turística consolidada (Molina Hoyo y Cánoves Valiente, 2011; Zambrano Mendoza, 2014). Están más dispuestos a pagar por calidad y buen servicio por lo que son poco tolerantes a un mal servicio, son exigentes y buscan comprobar la calidad del producto o servicio a adquirir. Es un segmento bastante sensible a las promociones de ventas, fundamentalmente descuentos en precio (Alén González, Domínguez Vila y Fraíz García, 2010). Martínez García (2013) señala, en cuanto a la valoración de los servicios turísticos, que este colectivo es más sensible y crítico que otros, en aspectos tales como la pulcritud y confortabilidad del alojamiento, la amabilidad del personal o los servicios de ayuda en el transporte de maletas. Muestran mayor preocupación por cuestiones de seguridad en sus viajes (Nielsen Nielsen, 2011).

En diferentes producciones académicas se utilizan distintos vocablos como adulto mayor, tercera edad-entendiendo este como un término superador de las connotaciones negativas de ancianidad o vejez (Miranda Montero, 1992), personas de edad avanzada, ancianos, senescente, senil, sexagenario, geronte, longevos, abuelo/a, jubilado, viejo, "senior" a manera de sinónimos. En este trabajo, se adoptó el de personas mayores siguiendo la concepción formulada por la OMT para referenciar al segmento de personas mayores de 60 a 80 años (Gala, 2017).

\section{Conceptualización de Oferta y demanda turística}

Existen diversas definiciones y clasificaciones de lo que se entiende por oferta turística; entre las que pueden distinguirse cuatro grandes grupos que componen la oferta turística: a) las atracciones; b) los accesos; c) las comodidades y entretenimientos y d) los servicios auxiliares.

Wallingre (2014) explica que se trata de un concepto muy amplio y señala que la definición propuesta por Milio Balanzá (2004) es propicia porque expresa que la oferta turística está "compuesta por el conjunto de productos, servicios y organizaciones que intervienen de forma activa en el sector turístico, e incluye como parte de ella la intermediación y la venta realizadas por los tours operadores y las agencias mayoristas y minoristas" (Wallingre, 2014, pp. 126-127).

Interesa señalar que la oferta turística tiene a los atractivos turísticos como su componente principal y otros que son los denominados periféricos, entre los que se incluyen las empresas turísticas, la infraestructura instalada y otras empresas que amplían la oferta local. 
Los atractivos turísticos son "aquellos objetos o acontecimientos capaces de motivar a las personas a abandonar su domicilio habitual para trasladarse, conocerlos y vivenciarlos" (Wallingre, 2004, p. 40). Estos pueden, a su vez, clasificarse en principales o aquellos que por sus características poseen una capacidad propia para atraer al turista y llevarlo a la toma de una decisión en su viaje y, secundarios o aquellos que por sí solos, salvo excepciones, no llegan a generar corrientes turísticas, pero que, integrados a los principales, contribuyen a realzar las cualidades de la zona.

En cuanto a la oferta turística periférica, según señala Milio Balanzá (2004), pueden indicarse:

- Las empresas turísticas básicas: aquellas cuyo objetivo primordial es proporcionar a la demanda existente los servicios directos de utilidad básica e indispensable para el desarrollo de la actividad turística. Entre las que se encuentran empresas de alojamiento y de viaje.

- Infraestructura e instalaciones públicas y privadas: los elementos físicos necesarios para el desarrollo de la actividad, ya sean públicos o privados. Permiten el acceso y uso de las anteriores y el disfrute de los recursos turísticos.

- Elementos complementarios: son empresas de carácter privado, aunque también pueden ser de gestión pública, que ofrecen a la demanda actividades diversas para que se sientan más atraídos por el producto ya que existe una mayor oferta complementaria.

\section{Delimitación de imaginario turístico}

El imaginario turístico es entendido como conjuntos estructurados o imprecisos de nociones, creencias, imágenes (César Arnaiz, 2007; Augé, 1998; MacCannel, 2007), metáforas y actitudes con los que se definen las situaciones y llevan a cabo sus planes de acción, a partir de modelos de pensamiento que los distintos actores sociales reciben y transmiten a través de la tradición, la educación, apreciación y la comunicación social.

En función de ello, importa mencionar que

la constitución del imaginario del turismo es entonces una construcción compleja, subjetiva, intervenida por la transferencia tanto de impresiones subjetivas captadas a través de experiencias de vida, como de datos recogidos de otras personas o medios de difusión. El imaginario recurre también a las construcciones propias de la representación, construcciones sustentadas por la imaginación, el sueño, la fantasía individual o colectiva (Hiernaux et al., 2002, p. 9).

Entonces, los imaginarios son fundamentales para comprender los modelos turísticos que existen en la actualidad cuestionando así la "tan famosa visión económica del turismo, 
donde el agente económico es quien determina el éxito de los modelos turísticos" (César Arnaiz, 2007, p. 15) puesto que el turista es quien escoge o no continuar consumiendo una oferta turística que se adecúe a sus necesidades y motivaciones.

\section{Caracterización de Victoria, Entre Ríos, Argentina}

El departamento Victoria, se ubica sobre el delta del Río Paraná en el sudoeste de la provincia de Entre Ríos, a la vera del riacho Victoria en la región mesopotámica de la Argentina. Dada su ubicación es una zona con topografía caracterizada por la presencia de lomadas, colinas y barrancas al río, que irrumpen en el ejido citadino.

Fundada en 1810, es una antigua ciudad colonial que tiene en su diseño urbano las características de lo establecido en la Ley de Indias presentando una marcada subdivisión en la cual se distinguen las siguientes zonas: Urbana, Quinto Cuartel, Abadía y alrededores, la Costa y la Rural y de Chacras. A propósito de ello, entre las características de su ejido urbano, es de destacar según señala Herrera (2004) que la zona urbana se presenta como un damero de construcciones con un trazado de calles rectas, las cuales presentan un continuo desnivel. Las características arquitectónicas de la localidad que presentan una mezcla de estilos colonial-español-francés y art noveau, conforman un importante atractivo, siendo los trabajos de herrería una de sus características más destacadas, que le dan el nombre de "ciudad de las rejas".

La ciudad de Victoria cuenta con una serie de atractivos turísticos que se ofrecen tanto desde la página web de la ciudad como desde la Dirección de Turismo municipal. Allí se incluye: la Abadía del Niño Dios, el Casino Victoria, el Centro Cívico, el Cerro La Matanza, la Costanera, el Mirador de la Virgen de Fátima, el Monte de Ombúes, el Museo de la Ciudad, el Museo Ovni, el Parque Termal "Victoria del Agua" y el Barrio del Quinto Cuartel.

Lima (2009) ha señalado que desde finales de la década del 80 se desarrolló una incipiente actividad turística con una marcada estacionalidad que estuvo asociada al turismo de estancia, de caza y pesca, religioso, y al carnaval en los meses estivales. Respecto de este último interesa mencionar que el carnaval es un evento cultural realizado entre los meses de enero y febrero de cada año que le da a Victoria el nombre de Capital Provincial del Carnaval de Entre Ríos. Este simboliza y sintetiza la herencia cultural propia del pasado de la comunidad -que se busca transmitir a las diferentes generacionesdestacando el espíritu popular del mismo, donde el público es parte del espectáculo, y la espuma y el papel picado conforman un elemento diferenciador de otros carnavales del país.

En líneas generales, en función de la información provista por los informantes clave de la Dirección de Turismo-sede Tiro federal, Victoria recibe 107.000 turistas al año. 
Reportan también que la ciudad es principalmente visitada por familias o grupos de amigos que se acercan por períodos cortos en busca de las diferentes alternativas turísticas que ofrece como así también se registra turismo de negocios y visitas a familiares.

La existencia de distintos atractivos, la infraestructura instalada, su cercanía a los dos principales centros emisores del país (se ubica a $236 \mathrm{~km}$ del Gran Buenos Aires y está vinculado a Rosario a través del Puente Rosario-Victoria) y su clima benévolo, la convierten en un destino sumamente interesante para el desarrollo de una oferta turística adecuada para el turismo de personas mayores pudiendo recibir visitantes durante todo el año.

\section{Caracterización del imaginario turístico de Victoria según las personas mayores}

Este segmento está conformado por personas de entre 60 y 80 años que disponen de mayor tiempo libre que otros segmentos y de recursos para viajar sin preferencias específicas de la época del año para trasladarse.

En el entramado de sus voces es posible observar que disfrutan de explorar, caminar, manifiestan querer conocer varios lugares. Juan de 66 años señala que "es una pena no haberlo podido ir a ver y caminar un poco entre los árboles del Monte de la matanza". En sus argumentaciones ponen de manifiesto que rompen la endogamia cotidiana. María de 70 años dice "venimos a pasear", lo que denota que aprecian actividades que les permitan moverse y estrechar lazos sociales con sus pares y otros argumentos como el de Francisca de 78 años recogen que "a la noche si querés hacer algo, no hay nada acá más que el casino. Así que vamos como para salir un poco".

Otros aspectos que son de su preferencia son la paz, tranquilidad, el trato amable y cortés como se observa en lo que dice Silvia de 62 años "volvería cada vez que pueda porque es tranquilo, la paz y me gusta, la gente nos ha tratado muy bien". Entre otros discursos se aprecia el de José de 69 años que dice "porque soy jubilado y viajo constantemente" o el de Juana de 71 años que menciona "porque el clima es muy bueno".

Manifiestan su gusto por la naturaleza, el entorno urbano y rural, como se lee a continuación en lo que menciona Raquel de 68 años "(la costanera) la elegimos para tomar mate, por la hermosa vista, por el contacto con la naturaleza". Estos argumentos permiten inferir la importancia de contar con distintas opciones de recreación que Roberto de 69 años sintetiza como "es tan lindo que mejor caminar y curiosear".

En el análisis de las respuestas sobre su perspectiva respecto a la oferta turística de la ciudad en el entramado de sus narraciones se puede leer que los atractivos que más visitan son: el Centro Cívico -respecto del cual destacan la Parroquia de la patrona local como otro atractivo, diferenciándolo del casco histórico, la Abadía, el Casino, la costanera y el Parque Termal. 
En su conjunto, del recorrido por el ejido urbano destacan las piezas de herrería ornamental, que es un pueblo tranquilo, lindo y pintoresco.

Respecto de los museos, pocos de los encuestados los han visitando y al dialogar con los registros de la propia perspectiva de las personas mayores que visitaron el lugar, los comentarios realizados permiten inferir que valoran más realizar actividades en movimiento o al aire libre. Algunas referencias de los encuestados son: “¿ir al museo? ¿Para qué? ¿Querés que me guarden ahí adentro? (mujer, 65 años)

Interesa señalar que la Abadía es el sitio que las personas mayores señalan elegir para comprar artículos de recuerdo de Victoria. En su práctica, le otorgan significación haciendo que la Abadía se convierta en parte del imaginario turístico de la ciudad. También es un atractivo casi obligado para quienes visitan la zona. Otra característica del perfil es que valoran la producción local, la profesionalidad de quienes lo hacen y la relación precio-calidad, según dicen: "hay que aprovechar porque estas cosas en casa no son tan buenas a estos precios" (hombre, 61 años). Estos artículos de recuerdo, no sólo contribuyen a la turistificación de la vida cotidiana sino que son los vectores de reencuentro con el imaginario turístico.

En las conversaciones informales, agregaron que es una pena que en la zona de la costanera no hubiera rampas que la hicieran más accesible. Mirta expresa "porque la elegimos para tomar mate, por la hermosa vista, por el contacto con la naturaleza". Es señalado como importante porque se infiere que están encerrados, no pasan mucho tiempo fuera de su lugar cotidiano de residencia.

Otro de los atractivos de Victoria es el Barrio del Quinto Cuartel que la amplia mayoría de las personas afirmaba no conocerlo o haber escucha de él. A su vez, no era ofrecido desde la Dirección Municipal de Turismo. Los comentarios de las personas que se acercaron fue "no hay nada para ver porque no sabes en verdad qué es lo que hay, nada ni nadie te lo explica" (mujer, 62 años). En este sentido, aparece la crítica a la falta de guía para apreciar lo que el lugar ofrece.

Por otro lado, en cuanto a uno de los atractivos naturales interesa señalar, acorde con quiénes han visitado el Cerro de La matanza, que "es lindo lugar (ya que) se puede caminar bien pero si llueve, agarrate porque se vuelve tobogán" (mujer, 70 años). Las valoraciones más negativas coinciden con personas mayores de 70 años. Estas referencias dan cuenta de los diferentes aspectos valorables que el segmento construye, da significación a su práctica y pone de manifiesto que consideran la actividad no solamente en el momento de su práctica turística sino en su imaginario acerca del lugar en la planificación y elección de su visita, lo representan con otros climas.

Se observó en la triangulación de datos que aquellos que no habían visitado los sitios naturales son los que se corresponden con el segmento de 70 años o más. Coinciden con 
aquellas personas que viajan a través del centro de jubilados, por lo que no tienen independencia en su traslado dentro de la ciudad.

Además se observa que este segmento disfruta de viajar en grupo o en pareja y prefieren trasladarse por cuenta propia. Cuando no puede hacerlo, dependen de los centros de jubilados y los viajes que estos organizan para viajar aunque prefieren lugares con buen clima.

En cuanto a la oferta turística periférica entre sus narraciones se encuentra que:

- Las empresas turísticas básicas como el alojamiento manifiestan la elección de establecimientos hoteleros de media categoría. Estos "sabios aficionados" señalan la estrechez de las habitaciones, lo resbaladizo de los baños y que en algunos casos, solo contaban con ducha "con una parecita alta y no había de dónde agarrarse" (mujer, 70 años). Nuevamente hacen referencia al concepto de accesibilidad. Aquellos que ya habían visitado la ciudad, indicaban que elegían el mismo establecimiento hotelero, a pesar de no cubrir totalmente sus necesidades porque "mejor malo conocido, que bueno por conocer" (hombre, 68 años).

- En infraestructura e instalaciones públicas y privadas existe una relación directa entre la apreciación respecto de la señalización y el estado de las calles. En estos casos en particular se observó que los hombres brindaron respuestas negativas como por ejemplo, en cuanto al estado de las calles que "está lleno de pozos y badenes". Por otro lado, las mujeres, menores de 70 años, respecto de la señalización dijeron que "no hay carteles ni de mano y contramano" (mujer, 65 años). Esta diferenciación en las percepciones está relacionada, podría decirse, con los roles que tiene cada uno en el viaje, donde el hombre es quien maneja y la mujer hace de guía "yo le digo es por acá o por allá" (mujer, 62 años). En algunos casos hicieron mención a que si se buscaba circular a pie, las veredas no están en condiciones y poseen grandes desniveles, "están muy rotas o venís caminando y de golpe escalones altos, haces tres pasos y otra vez escalones, casi me caigo" (hombre, 61 años). Si bien esto se debe a las características topográficas victorienses que fueran descriptas anteriormente, interesa señalar la incomodidad que genera para la circulación en las personas longevas.

Por otro lado, en cuanto a las rampas indicaron que "no las he notado" (mujer, 63 años), incorporando además a su declaración que esto se debía a que "no las necesita" (mujer, 63 años). Estas referencias ponen de manifiesto que polemizan con la representación social que los califica como personas desvalidas, inactivas.

Además, aquellos que valoraron como regulares a las rampas, coincide con personas más longevas, haciendo que las mismas sean más necesarias, por lo que perciben más su ausencia que otros segmentos, "las rampas son pocas en los lugares a los que nos llevan" (hombre, 76 años). 
En función de las referencias se recoge a manera de síntesis respecto la infraestructura urbana que "poner los frentes de las casas más pipi cucú, hacen falta mejoras en las calles como así también en la señalización sino no llegas” (mujer, 63 años).

- Elementos complementarios

-Dirección de turismo: manifestaron que la atención recibida no fue cortés sino simplemente realizaron la entrega del plano y la mención de los principales atractivos sugeridos para este segmento como son el Parque Termal, el Centro Cívico, la costanera y la Abadía. Comentan que fueron "apáticos, poco amables y desatentos" (mujer, 62 años), "molestaba que pidiéramos repitieran las indicaciones" (hombre, 76 años) o "nos dieron un mapa que no se ve nada" (mujer, 69 años).

-Parque Termal: objeta la accesibilidad física del predio. Por una parte, señalan que por la inclinación de las rampas y por otra, su extensión, "son muy largas para caminar al sol con todos los petates" (mujer, 78 años), se hace dificultoso transitarlas. En la administración oral del cuestionario los encuestados expresaron como aspectos negativos de dicho atractivo: la falta de espacios verdes y que la gran dimensión del predio hace que las distintas facilidades que ofrece queden alejadas unas de otras. Aún cuando este segmento sea activo y pueda valerse por sí mismo señalan que "hay que caminar mucho" (mujer, 69 años); critican que solo había una piscina funcionando en época invernal, que es cuando más podrían disfrutarlas; se quejan de los malos olores en las piletas. Respecto de esto se indagó con mayor profundidad, considerando que los mismos se asocian al azufre presente en el agua termal. Las respuestas obtenidas enfatizaban que "el agua termal tiene olor fuerte pero las de Federación y Colón no" (hombre, 61 años). Nuevamente es posible observar su juicio crítico y experimentado. Señalaron como un aspecto en detrimento de la oferta del atractivo que el mismo no posee alojamiento propio, siendo esto un servicio que sería valorado por este segmento en particular. Aquí se aprecia que son capaces de criticar con fundamentos, argumentos que provienen de sus experiencias y ese saber de aficionado, es lo que les da peso relativo al momento de dar su argumentación de un destino por sobre otro.

-Casino: De este señalan que es de las pocas alternativas que hay para salir por lo que también desafía la representación social que se tiene de este segmento.

-Establecimientos gastronómicos: La apreciación general es positiva. Aquellos que los consideraron regulares señalaron que no hay correlación adecuada entre los precios y la calidad, expresando que esta última no es la esperada para el costo de la comida. Nuevamente es posible observar cómo el segmento construye sus representaciones en función de lo que recibe, tiene la capacidad de comparar, de demandar. Asimismo, 
dado que es una localidad litoraleña en su imaginario turístico aparece el producto ictícola local como parte de la oferta gastronómica por lo que, al no encontrarlo, en su discurso critica que "no hay dónde comer pescado de río fresco" (hombre, 66 años).

Nuevamente es posible observar cómo el segmento crea sus representaciones en función de lo que recibe y tiene la capacidad de comparar, de demandar. Este aspecto se convierte en una delimitante de los recorridos que pueden realizar, impidiendo que puedan disfrutar del destino en su totalidad, volviéndolo menos amigable, acogedor, hospitalario y restrictivo para este subsegmento de personas mayores.

Las prácticas descriptas dan cuenta del buen estado de salud del segmento puesto que siguen manteniendo procesos cognitivos relacionados con la planificación, organización, manejo del tiempo a mediano y largo plazo, su independencia. Tienen y aplican su sentido crítico, reflexionan con pensamiento propio sobre la oferta turística, comparan opciones y experiencias en otros sitios para una toma de decisión informada y satisfactoria. Asimismo, a partir de las experiencias de otros forman su propio imaginario turístico de la localidad en su actividad pre turística por lo que las experiencias de sus pares son otra fuente de información para el armado de sus viajes.

De igual forma, en la construcción de su propia experiencia critican aquellos aspectos que no los satisfacen tales como la falta de señalización, el estado del ejido urbano, la representación hegemónica que los califica como "viejos" lo cual conlleva que haya atractivos que les ofrecen conocer. En la construcción de sus imaginarios, se plantean desafíos y manifiestan su curiosidad que los motiva racionalmente a buscar y construir nuevas experiencias, son "descubridores tranquilos" (Hernández Mogollón, 2008), curiosos y ávidos de nuevos desafíos.

Por otro lado, estas personas mayores, como parte de su imaginario turístico en tanto construyen su experiencia y organizan su realidad, comparan la que viven en Victoria con otros destinos. Esto permite observar dos aspectos: por una parte, sus viajes y por otra, sus representaciones y motivaciones a partir de las cuales seleccionan el sitio al que viajarán, sus consumos, el nivel de calidad/satisfacción que los conforma.

Se observa que el imaginario turístico que tiene el segmento sobre la oferta es que, aún cuando no se adecúa completamente a sus necesidades prefieren continuar eligiendo lo seguro. En consecuencia se pone de manifiesto que en sus interacciones con pares y otros, guían su acción y, por ejemplo, lamentan que no les ofrezcan otras alternativas allí, tanto para realizar actividades en la naturaleza o recreativas nocturnas. Exponen así sus motivaciones emocionales relacionadas con el ocio, curiosear, descansar, conocer nuevos lugares, estrechar lazos sociales y sus motivaciones racionales. En sus construcciones dan cuenta de algunas de sus necesidades y demandas que no son atendidas adecuadamente. 


\section{Propuesta de adecuaciones a la oferta turística de Victoria}

En función de las características descriptas del perfil del turista/persona mayor, recuperando su propia voz, tras haber relevado la oferta turística de Victoria, y habiendo realizado un análisis de las narraciones de las personas mayores que visitaban la ciudad, se sugieren en este punto, una serie de adecuaciones para la oferta turística de la ciudad bajo estudio a partir de las argumentaciones de las personas mayores con el propósito de sentar bases para adecuar la oferta turística a este segmento.

En función de ello, en cuanto a la oferta turística principal, los atractivos, se sugiere mejorar la accesibilidad y cartelería, como así también incorporar guías, servicios médicos de urgencia.

En lo que respecta al alojamiento, en el análisis de los distintos discursos se sugiere incorporar medidas que permitan mejorar la accesibilidad. Asimismo, en vistas de la oferta local y los intereses del segmento, podrían brindarse otras opciones para el uso del tiempo libre.

En cuanto a las empresas intermediarias de viajes sería interesante el desarrollo de alianzas estratégicas que dinamicen el turismo local.

Con relación a la Infraestructura e instalaciones se observa que el segmento valora lo estético y la accesibilidad por lo que mejorar fachadas, señalética y estado de las calles, sería recomendable para una mejor apreciación del destino.

Finalmente, se sugiere para los elementos complementarios de la oferta que en la Dirección de Turismo se mejore la atención dada a los turistas. En particular, brindar información de manera completa acerca de las distintas opciones que ofrece Victoria tales como los espacios al aire libre que, según lo recogido en las narraciones son espacios que este segmento disfruta y valora.

Asimismo, del Parque termal se sugiere distintas modificaciones que adecúen al segmento. Entre las mismas se recomienda incorporar mayor cantidad de espacios verdes con arboleda, desarrollar tramos que se intercalen con espacios para descansar. En vistas que se critican los malos olores, una forma de desalentar esas apreciaciones sería reforzar la cartelería explicativa respecto de los olores de las termas. Por otra parte, para atender las demandas insatisfechas de esta tipología turística se sugiere incorporar otros servicios como el alquiler de batas y considerar la instalación de alojamiento en la zona próxima al complejo termal.

Otro de los elementos de la oferta es el Casino Victoria. El análisis de las apreciaciones del colectivo permite inferir que sería beneficioso para la empresa y los 
turistas que se busque desarrollar estrategias de comercialización que diversifiquen su oferta de entretenimiento considerando los intereses del segmento y la accesibilidad. También, puesto que manifiestan la escasez de alternativas de divertimento en horarios nocturnos, para fomentar la participación, se sugiere el desarrollo de actividades lúdicas y recreativas en, por ejemplo, los museos en horarios vespertinos para presentar alternativas de entretenimiento.

En cuanto a los establecimientos gastronómicos, se sugiere la incorporación de platos con productos y materias primas locales dado que el segmento valora lo telúrico y busca otras opciones gastronómicas distintas a las que tiene en su lugar de origen.

Para finalizar con las sugerencias de adecuaciones a la oferta complementaria, se sugiere para los locales comerciales la realización de visitas a fábricas de regionales o el diseño de circuitos de artesanos, para así atraer a los visitantes que llegan de manera autónoma a la ciudad. En este sentido, se sugiere establecer alianzas comerciales con agencias de turismo que ofrezcan paquetes a este segmento para que realicen un circuito de compras por la zona céntrica como así también se sugiere la instalación de una Casa de artesanos.

\section{Reflexiones finales}

A través de la aplicación del abordaje plurimetodológico se ha podido confirmar que la oferta turística actual no satisface las exigencias del segmento y que el turista persona mayor es crítico del producto que se le ofrece y percibe.

Asimismo, los resultados permiten afirmar que la ciudad de Victoria resulta ser un destino atractivo para este segmento y que la misma posee diferentes alternativas que podrían ajustarse mejor a sus necesidades a partir de la voz de este segmento. El perfil de esta modalidad turística podría volverse fiel a dicha ciudad, pero será de relevancia que se adecúe la oferta en función de su perspectiva, considerando sus características intrínsecas al construir su propio tiempo de ocio.

A partir de los resultados de esta investigación se propone la adecuación de la oferta turística de Victoria, Entre Ríos, en respuesta al imaginario turístico del segmento de personas mayores que interpelan a la oferta del destino, para lograr una diferenciación que sea percibida y valorada por ellos.

Por otro lado, es posible observar a partir de los resultados que dentro de este segmento se pueden distinguir dos subsegmentos: aquellos de 60 a 69 años y los de más de 70. El primero presenta hábitos de autonomía. Ello se observa en la manera en la que organizan sus viajes, cómo se informan acerca de un destino consultando con otras personas, utilizando la tecnología y páginas de Internet y la forma que se trasladan al destino. Se trasladan por cuenta propia y respecto a la infraestructura urbana reclaman 
mejor señalización y estado de calles. No muestran aún de manera generalizada, impedimentos físicos para trasladarse.

Por otra parte, el de 70 a 80 años. Presentan más generalizadamente algún tipo de dificultad en su motricidad y demandan mejor accesibilidad en el destino. Es crítico con las limitaciones que les supone la falta de diseños inclusivos que le den la posibilidad de disfrutar el destino como ellos escojan; son más conscientes de la accesibilidad y se representan los lugares en distintos momento. En cuanto a su menor autonomía, la misma se observa en el hecho que relegan en otros la tarea pre viaje y de traslado y, conforme la edad es más avanzada, hacen referencia a su cansancio.

Finalmente, los pronósticos apuntan que las personas mayores del futuro, además de constituir un importante porcentaje de nuestra sociedad, manifestarán diferentes características a la cohorte generacional actual, ya que tendrán un mayor nivel de vida, poseerán un nivel cultural claramente superior, serán más participativos y tendrán mayor concienciación sobre la vejez y preparación para la misma por lo que es posible afirmar que la adecuación de la oferta turística permitirá satisfacer las necesidades emergentes. Por lo expuesto, se vuelve necesario que tanto gobierno local como sector privado lleven acciones conjuntas para mejorar las prestaciones en relación a brindar mayor confort, servicios, atención, especificidad para atender las motivaciones de descanso e intereses del segmento de personas mayores que construye su propio tiempo de ocio en función de sus experiencias volviéndola propia.

\section{Referencias bibliográficas}

Alcalá, A. (2001). La praxis andragógica en los adultos de edad avanzada. Informe de investigaciones educativas (15) 1 y 2, pp. 1-19.

Alén González, M. E., Domínguez Vila, T. y Fraíz García, A. (2010). El turismo senior como mercado emergente. Cuadernos de turismo (26), pp. 9-24.

Aromando, J. (2002) Adultos Mayores en MERCOSUR: Perspectivas de desarrollo educativo y cultural. Foro mundial de ONGs para el envejecimiento. I asamblea mundial del envejecimiento. Naciones Unidas, Madrid.

Augé, M. (1998). El viaje imposible. El turismo y sus imágenes. (Trad.: A. L. Brixio). España: Gedisa.

César Arnaiz, F. (2007). Ciudades Turísticas Desarrollo e imaginarios Careyes y Nuevo Vallarta. México: Centro Universitario de la Costa- Universidad de Guadalajara. 
Chardon, M.C. (2005). "Armando Proyectos a los... ¿70?" Características de Calidad de Vida de los Adultos Mayores. Universidad Nacional de Quilmes. Bernal.

Chardon, M.C. (2011). Aprendizaje y construcción de subjetividad. En Elichity, N.: La Psicología Educacional como instrumento de análisis y de intervención. Diálogos y entrecruzamientos. Buenos Aires: Noveduc.

Gala, V. (2017). Perspectivas del turismo de personas mayores en Victoria, Entre Ríos. Su voz como sujetos activos que construyen su propio tiempo de ocio. Tesis de maestría en Desarrollo y Gestión del Turismo con orientación en Destinos Turísticos. Universidad Nacional de Quilmes, Buenos Aires, Argentina. Inédito.

Goycoolea Prado, R. (2004). Los imaginarios turísticos en la configuración urbana. Revista científica de América Latina y el Caribe 6 (8).

Herrera, M. (2004). Plan Estratégico de Victoria (Ciudad Victoria - Prov. Entre Ríos) Trabajo Final. Intervención Urbanística. Universidad Nacional de Rosario. Inédito.

Hiernaux, N.; Cordero, A. y Van Duynen Montijn, L. (2002). Imaginarios sociales y turismo sostenible. Cuaderno de Ciencias Sociales 123.

Hiernaux, D. (2007). Los imaginarios urbanos: de la teoría y los aterrizajes en los estudios urbanos. Revista eure 33 (99), pp.17-30.

lacub, R. (2012). Proyectar la vida: el desafío de los mayores. Buenos Aires: Manantial SRL.

Le Serre, D. (2008). Who is the elderly Consumer? Graduate School of Business Administration. Francia: University of Rennes.

Lima, M. (2009). Industria turística victoréense. Análisis económico período 1998-2007. Tesis de Grado para Licenciatura en Economía. Universidad del Centro Educativo Latinoamericano, presentada en Rosario, Santa Fé, Argentina.

MacCannell, D. (2007). Lugares de encuentro vacíos. Barcelona: Melusina. 
Maldonado Acosta, S. (2012). Análisis de la demanda de turismo de afiliados a las instituciones INJUPEMP, AJUPEUNAH y AORFFAA. Proyecto especial presentado como requisito parcial para optar al título de Ingeniero en Desarrollo Socioeconómico y Ambiente en el Grado Académico de Licenciatura. Zamorano, Honduras.

Martínez García, E. (2013). El turista sénior en Europa: Actualidad y futuro. Revista Iberoamericana de Turismo (RITUR) 2 (1), pp. 38-56.

Milio Balanzá, I. (2004). Diseño y comercialización de productos turísticos locales y regionales. Madrid: Thomson Paraninfo.

Miranda Montero, J. (1992). Las vacaciones de la tercera edad. Un tipo específico de turismo. Cuadernos de Geografía 51, pp. 111-124.

Molina Hoyo, M. y Cánoves Valiente, G. (2010). Turismo Accesible, Turismo Para Todos: La Situación en Cataluña y España. Cuadernos de Turismo 25, pp. 25-44.

Montaner Montejano, J. (2002). Psicosociología del turismo. Madrid: Editorial Síntesis.

OMT (1996). Carta de Recife (Brasil) sobre turismo de personas mayores.

Vivanco Naranjo, E. (2012). Análisis de las tendencias turísticas del segmento de tercera edad en la ciudad de Quito y propuesta para la oferta en agencias de viajes. Tesis de grado. Carrera de Administración Hotelera y Turística. Universidad Tecnológica Israel, Quito, Ecuador. Recuperado de: http://repositorio.uisrael.edu.ec/handle/47000/624

Nielsen Nielsen, K. (2011). El turismo de la tercera edad en los destinos turísticos consolidados: el caso de la costa del sol. Universidad de Málaga. Espacios y destinos turísticos en tiempos de globalización y crisis. Vol. II: 383-398. Universidad Carlos III. Madrid.

Stake, R. (2005). Investigación con estudios de casos. Madrid: Morata SRL.

Wallingre, N. (1998). El Turismo Social, una alternativa para la realización de la tercera edad. Revista Universidad Kennedy, Enfoques de Turismo y sus modalidades 1, 1-9.

Wallingre, N. (2004). Problemas turísticos contemporáneos. Carpeta de trabajo. Universidad Nacional de Quilmes, Bernal. 
Wallingre, N. (2009). La definición de productos en los destinos turísticos en Desarrollo y gestión de destinos turísticos. Políticas y estrategias. Bernal: Universidad Nacional de Quilmes Editorial.

Wallingre, N (2014) Instrumentos para el diagnóstico integral de la oferta en destinos turísticos. Gestión de municipios turísticos. Instrumentos básicos de acción. Universidad Nacional de Quilmes. Buenos Aires.

Zambrano Mendoza, G. (2014). Propuesta para la creación de un paquete turístico destinado a personas de la tercera edad y su incidencia en el servicio de atención al cliente en los jubilados del Cantón Chone, provincia de Manabí. Facultad de Especialidades Empresariales. Universidad Católica de Santiago de Guayaquil, Ecuador. Recuperado en: http://repositorio.ucsg.edu.ec/handle/3317/2299 